\title{
Limited Management of Systemic Erythematosus Lupus in Madagascar
}

\author{
Fandresena Arilala Sendrasoa*, Irina Mamisoa Ranaivo, Naina Harinjara Razanakoto, \\ Malalaniaina Andrianarison, Onivola Raharolahy, Lala Soavina Ramarozatovo, \\ Fahafahantsoa Rapelanoro Rabenja
}

Department of Dermatology, University Hospital Joseph Raseta Befelatanana, Antananarivo, Madagascar

\section{Email address:}

nasendrefa@yahoo.fr (F. A. Sendrasoa), irinamami@yahoo.fr (I. M. Ranaivo), harnjart9@gmail.com (N. H. Razanakoto), aina_andrianarison@yahoo.fr (M. Andrianarison), oni.raha@gmail.com (O. Raharolahy), lramarozatovo@gmail.com (L. S. Ramarozatovo), frapelanoro@yahoo.fr (F. R. Rabenja)

${ }^{*}$ Corresponding author

\section{To cite this article:}

Fandresena Arilala Sendrasoa, Irina Mamisoa Ranaivo, Naina Harinjara Razanakoto, Malalaniaina Andrianarison, Onivola Raharolahy, Lala Soavina Ramarozatovo, Fahafahantsoa Rapelanoro Rabenja. Limited Management of Systemic Erythematosus Lupus in Madagascar. International Journal of Biomedical Engineering and Clinical Science. Vol. 3, No. 4, 2017, pp. 48-51. doi: 10.11648/j.ijbecs.20170304.14

Received: October 31, 2016; Accepted: December 27, 2016; Published: October 24, 2017

\begin{abstract}
Systemic lupus erythematosus (SLE) is a chronic autoimmune disease that involves multiple organs and has alternating periods of flare-ups and quiescence. SLE requires multiple paraclinical and therapeutic investigations that are not accessible by Malagasy patients. We aim to assess the monthly direct cost in SLE referring to international recommendations. The cost of paraclinical exams and treatment expenses were estimated as a percentage of the MMMS (Malagasy Minimum Monthly Salary). According to international recommendations, the cost of first-line paraclinical exams for SLE diagnosis was $274,2 \%$ of the MMMS. The costs of diagnostic tests were $110,9 \%$ and $923,4 \%$ of the MMMS to research renal and neurological damage, respectively. The monthly cost of pharmacological therapies ranged from $132,2 \%$ to $205,9 \%$ of the MMMS, depending on the severity of SLE. Clinical examination and affordable paraclinical exams were fundamental in our practice to manage systemic lupus erythematosus lupus. Appropriate recommendations for emergent countries should be come up.
\end{abstract}

Keywords: Systemic Lupus Erythematosus, Cost, International Recommendations

\section{Introduction}

Systemic lupus erythematosus (SLE) is a complex disease with variable presentations. Prevalence rates was 11 per 10000 persons in Madagascar. SLE has alternating periods of flare-ups and quiescence [1]. Furthermore, SLE requires multiple paraclinical and therapeutic investigations. SLE is a chronic disorder, and the condition of patients with SLE may worsen if major organs are affected [2]. Over the last three decades, however, the diagnosis and management of SLE have improved; the 10year survival rate has recently been estimated at about $90 \%$ [3]. This means that patients with SLE are living longer, and the burden of the disease at both the personal and societal levels is expected to increase [4].
Different therapeutic classes are used, alone or in combination in SLE: anti-malarial, non steroidal antiinflammatory, corticosteroids, immunosuppressive agents and biotherapy $[5,6]$. Data of direct cost in SLE are not available in Madagascar. Developed countries issue recommendations regarding SLE aren't constantly appropriate for emergent countries $[1,5]$. We suggest some remarks concerning the management of SLE in Madagascar, taking account of scientific data, medical ethics, equality and equity. We assessed the monthly direct cost in SLE if we were follow international recommendations for the management of SLE.

\section{Methodology}

We estimated the cost of paraclinical exams and treatment 
which are available in Madagascar, according to SLE damage. Then, we have estimated these costs as a percentage of the MMMS (Malagasy minimum monthly salary: 144 $000 \mathrm{Ar}=$ USD 43). The cost of investigations for differential diagnosis was not evaluated.

\section{Results}

The cost of first-line paraclinical exams for SLE diagnosis was $274,2 \%$ of the MMMS. Table 1 shows the details of first-line paraclinical exams. Other paraclinical exams such as antibodies of soluble nuclear antigens, antiphospholipid antibodies, anti U1RNP and cryoglobulinemia are very rarely done in first time; the cost of these paraclinical exams was $229 \%$ of the MMMS (Table 2).

The costs of diagnostic tests were $110,9 \%$ and $923,4 \%$ of the MMMS to research renal and neurological damage, respectively. The cost of CT exam (head or abdominal CT, CT angiography) ranged from $173,6 \%$ to $347,2 \%$ of the MMMS. Head MRI was exceptionally made by Malagasy patients because its costs was $694,4 \%$ of the MMMS. Table 3 shows the details of paraclinical exams to research visceral damage.

The monthly cost of pharmacological therapies ranged from $132,2 \%$ to $205,9 \%$ of the MMMS, depending on the severity of SLE (Table 4). For patients with renal damage, the monthly cost of pharmacological therapies was $239 \%$ of the MMMS if we follow international recommendations. Du fait de la non disponibilité du MMF et de l'Azathioprine à Madagascar, the monthly cost of our own treatment regimen was $171 \%$ of the MMMS

Table 1. Cost of first-line paraclinical exams.

\begin{tabular}{ll}
\hline Designation & Cost/MMMS (\%) \\
\hline Blood count + ESR+ CRP & 14,5 \\
Creatininemia + Natremia + Kalemia & 10,4 \\
Serum protein electrophoresis & 34,7 \\
Fibrinogen & 7 \\
Proteinuria & 3,4 \\
HLM base & 7 \\
Antinuclear antibody & 34,7 \\
Anti-dsDNA antibodies & 55,5 \\
Complementemia & 100 \\
Thorax X-ray & 7 \\
\hline
\end{tabular}

Table 2. Cost of second paraclinical exams.

\begin{tabular}{ll}
\hline Designation & Cost/MMMS (\%) \\
\hline Antibodies of Soluble Nuclear Antigens & 69,4 \\
Antiphospholipid antibodies & 69,4 \\
Anti U1RNP & 55,5 \\
Cryoglobulinemia & 34,7 \\
\hline
\end{tabular}

Table 3. Costs of paraclinical exams to research visceral damage.

\begin{tabular}{ll}
\hline Designation & Cost/MMMS (\%) \\
\hline Renal damage & \\
Urine sediment & 10,4 \\
Proteinuria & 3,4 \\
Renal ultrasound & 27,7 \\
Renal biopsy & 69,4 \\
Neuropsychiatric damage & \\
\hline
\end{tabular}

\begin{tabular}{ll}
\hline Designation & Cost/MMMS (\%) \\
\hline EEG & 41,6 \\
Head CT & 173,6 \\
Head MRI & 694,4 \\
CSF analysis & 13,8 \\
Cardiac damage & \\
ECG & 7 \\
Doppler echocardiography & 69,4 \\
Respiratory damage & \\
PFTs/ DLCO & 27,7 \\
CT angiography & 347,2 \\
Digestive damage & \\
ALAT, ASAT, GGT, PAL & 11,1 \\
Abdominal ultrasound & 27,7 \\
Abdominal CT & 173,6 \\
Hematological damage & \\
Bone marrow & 7 \\
Hemostasis tests & 9,7 \\
\hline
\end{tabular}

PFTs: Pulmonary function tests

DLCO: Diffusion capacity for carbon monoxide

Table 4. Treatment expenses.

\begin{tabular}{lll}
\hline Designation & Usual dose & Monthly cost/MMMS (\%) \\
\hline Prednisone 20mg & $50 \mathrm{mg} / \mathrm{j}$ & 39 \\
Methylprednisolone inj & $500 \mathrm{mg} / \mathrm{j}$ for & 39 \\
$120 \mathrm{mg}$ & 3 days & \\
Hydroxychloroquine & $400 \mathrm{mg} / \mathrm{j}$ & 37,5 \\
Cyclophosphamide & $500 \mathrm{mg} / \mathrm{month}$ & 27,7 \\
Methotrexate & $10 \mathrm{mg} /$ week & 7 \\
Azathioprine & Not available & \\
Mycophenolate Mofetil & Not available & \\
Potassium & $600 \mathrm{mg} / \mathrm{j}$ & 14 \\
Calcium/Vitamin D & $1000 / 800 \mathrm{UI}$ & 14 \\
Sunscreen & & 27,7 \\
\hline
\end{tabular}

\section{Discussion}

Several international studies published in the past two decades have explored the impact of SLE on the health care system and society. In particular, cost-of-illness studies have attempted to estimate a cost for SLE management in North America, Europe and Hong-Kong [7, 8]. Despite high interest in SLE research, there is a lack of data on the cost of care of SLE especially in developing countries like Madagascar.

The SLICC criteria for SLE classification requires fulfillment of at least four criteria, with at least one clinical criterion and at least one laboratory criterion or biopsyproven lupus nephritis with positive ANA or anti-DNA [9]. However, due to high cost of immunological examination, respectively, fifty four percent and $43 \%$ of SLE patients have been able to do AAN and anti-dsDNA antibodies according to a study enrolled in Department of Dermatology, University Hospital Joseph Raseta, Antananarivo, Madagascar. None of SLE patients with abnormal urinary sediment had kidney biopsy [10]. In our daily practice, we retain the diagnosis of SLE through physical and biological signs (accessible by our patients), with high specificity for this disease (Table 5). 
Table 5. Specificity and sensibility of each criterion for SLE [9].

\begin{tabular}{lll}
\hline Criterion & Specificity (\%) & Sensibility (\%) \\
\hline Malar rash/photosensitive & 80,1 & 65,2 \\
rash/acute cutaneous lupus & 93,6 & 19,7 \\
Discoid rash & 92,1 & 44,2 \\
Oral ulcers & 95,7 & 31,9 \\
Nonscarring alopecia & 97,2 & 35,2 \\
Serositis & 43,6 & 79 \\
Arhtritis & 96,4 & 32,9 \\
Renal damage & 99,0 & 5,5 \\
Neurological damage & 99,5 & 7,1 \\
Hemolytic anemia & 94,8 & 46,4 \\
Leukopenia & 81,6 & 49,0 \\
Lymphopenia $<1500 / \mathrm{mm} 3$ & 94,7 & 17,0 \\
Lymphopenia $<1000 / \mathrm{mm} 3$ & 98 & 13,5 \\
Thrombocytopenia &
\end{tabular}

To assess disease activity, the different scores such as SLEDAI, SLAM, ECLAM, BILAG [11] are not used in Madagascar due to the high cost of immunological tests. We value clinical signs and ESR to monitor SLE in routine practice. SLE is a chronic autoimmune disease which require long-term management and lifetime follow-up. Furthermore, during disease flares, the drug is very expensive. Background treatment and avoidance of predisposing factors help our patient to limit disease flares.

As recommended by the Task Force Panel of ACR recommendation 2012, all patients with clinical evidence of active lupus nephritis, previously untreated, should undergo renal biopsy (unless strongly contraindicated) so that glomerular disease can be classified by current ISN/RPS classification. In addition, disease can be evaluated for activity and chronicity and for tunular and vascular changes. However, the availability of renal biopsy is limited in Madagascar due to the lack of technical facilities. After the elimination of other cause of urinary sediment abnormalities and / or renal failure, the diagnosis of lupus nephritis was made. As recommended by the Task Force Panel of ACR recommendation 2012, the treatment is based in large part on the classification of type of lupus nephritis by these ISN/RPS criteria. For induction therapy, glucocorticoid (GC) IV for 3 days was combined with Mofetil Mycophenolate (MMF) or cyclophosphamide (CYC), followed by maintenance with MMF or Azathioprine with or not oral corticosteroid [12]. However, MMF and Azathioprine are not available in Madagascar. We adopt the following treatment regimen: monthly administration of CYC IV and GC IV followed by oral corticosteroids for the induction therapy (during 6 months) and once every 3 months for maintenance during 2 years.

Several studies showed that medical direct cost increases with the severity of SLE. SLE patients with flares, renal [13, 14], neuropsychiatric [15] or pulmonary damage incurred higher direct costs. Madagascar minimum wage can't cover the treatment of SLE. All wages contributes to family monthly expenses, medical care take the last place. While we did not assess the indirect cost of SLE, it obviously would have an impact on the economy. The occurrence of disease flares increases the amount of absenteeism, which reduce the production yield.

The development of "Club Malagasy lupus" could help patients with SLE disease. Twinning with others associations could facilitate importation of drugs which are unavailable in Madagascar.

\section{Conclusion}

Appropriate recommendations for emergent countries should come up and studies focused on the cost/effectiveness should be carried out in developing countries like Madagascar. The improvement of initial and continuing medical education, emphasizing the interest and fundamental role of clinical examination and appropriate use of paraclinical exams should be enhanced.

\section{References}

[1] Doria A, Zen M, Canova M, Bettio S, Bassi N, Nalotto L et al. SLE diagnosis and treatment: when early is early. Autoimmun Rev 2010; 10 (1): 55-60.

[2] Zhu TY, Tam LS, Li EK. The socioeconomic burden of systemic lupus erythematosus: state-of-the-art and prospects. Pharmacoeconomic Outcomes Res 2012; 12: 53-69.

[3] Cervera R, Khamashta MA, Font J et al. Morbidity and mortality in systemic lupus erythematosus during a 10-year period: A comparison of early and late manifestations in a cohort of 1000 patients. Medicine (Baltimore) 2003; 82: 299308.

[4] Lau CS, Mak A. The socieconomic burden of SLE. Nat Rev Rheumatol 2009; 5: 400-404.

[5] Bertrias G, Ioannidis J. P, Boletis J, Bombardieri S, Cervera $\mathrm{R}$, Dostal $\mathrm{C}$ et al. EULAR recommendations for the management of systemic lupus erythematosus. Report of a Task Force of the EULAR Standing Committee for International Clinical Studies Including Therapeutics. Ann Rheum Dis 2008; 67: 195-205.

[6] Mosca M, Tani C, Aringer M, Bombardieri s, Boumpas D, Brey $\mathrm{R}$ et al. EULAR recommendations for monitoring patients with systemic lupus erythematosus in clinical practice and in observational studies. Ann Rheum Dis 2010; 69 (7): 1269-74.

[7] Clarke AE, Panopalis P, Petri M, Manzi S, Isenberg DA, Gordon $\mathrm{C}$ et al. SLE patients with renal damage incur higher health care costs. Rheumatology 2008; 47: 329-33.

[8] Zhu TY, Tam LS, Lee VW, Lee KK, Li EK. The impact of flare on disease costs of patients with systemic lupus erythematosus. Arthritis Rheum 2009; 61: 1159-67.

[9] Petri M, Orbai A. M, Alarcon G. S, Gordon C, Merrill J. T, Fortin P. R et al. Derivation and validation of the Systemic Lupus International Collaborating Clinics Classification Criteria for Systemic Lupus Erythematosus. Arthr Rheum 2012; 64 (8): 2677-86.

[10] Sendrasoa F. A. Comparative analysis of acute cutaneous lupus erythematosus and chronic cutaneous lupus erythematosus. Madagascar: DEFS Memories, 2015; ํ307. 
[11] Romero-Diaz J, Isenberg D, Ramsey-Goldman R. Measures of adult systemic lupus erythematosus. Arthritis Care Res 2011; 63 (11): doi: 10.1002/acr. 20572.

[12] Hahn B. H, McMahon M. A, Wilkinson A, Wallace W. D, Daikh D. I, Fitzgerals J. D et al. American College of Rheumatology guidelines for screening, treatment, and management of lupus nephritis. Arthritis Care Res 2012; 64 (6): 797-808.

[13] Wilson EC, Jayne DR, Dellow E, Fordham RJ. The costeffectiveness of mycophenolate mofetil as firstline therapy in active lupus nephritis. Rheumatology 2007; 46 (7): 1096-101.
[14] Aghdassi E, Zhang W, St-Pierre Y, Clarke AE, Morrison S, Peeva $\mathrm{V}$ et al. Healthcare cost and loss of productivity in a Canadian population of patients with and without lupus nephritis. J Rheumatol 2011; 38 (4): 658-66.

[15] Zhu TY, Tam LS, Lee VW, Lee KK, Li EK. Systemic lupus erythematosus with neuropsychiatric manifestations incurs high direct costs: a cost-of-illness study in Hong Kong. Rheumatology 2009; 48 (5): 564-8. 